\title{
Author Correction: Phylogenomic analysis sheds light on the evolutionary pathways towards acoustic communication in Orthoptera
}

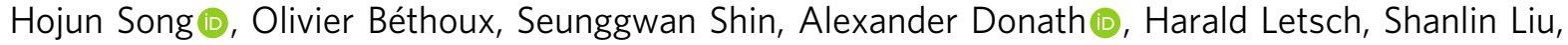

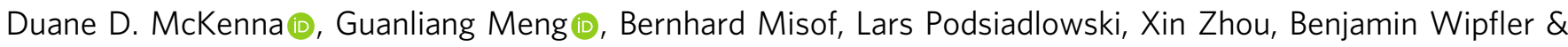
Sabrina Simon (1)

Correction to: Nature Communications https://doi.org/10.1038/s41467-020-18739-4, published online 2 October 2020.

The original version of this Article contained an error in Fig. 3, in which the types of tegmino-tegminal stridulation in Gryllidea and in Tettigonioidea shown on the right side of the phylogeny were reversed. The correct version of Fig. 3 is:

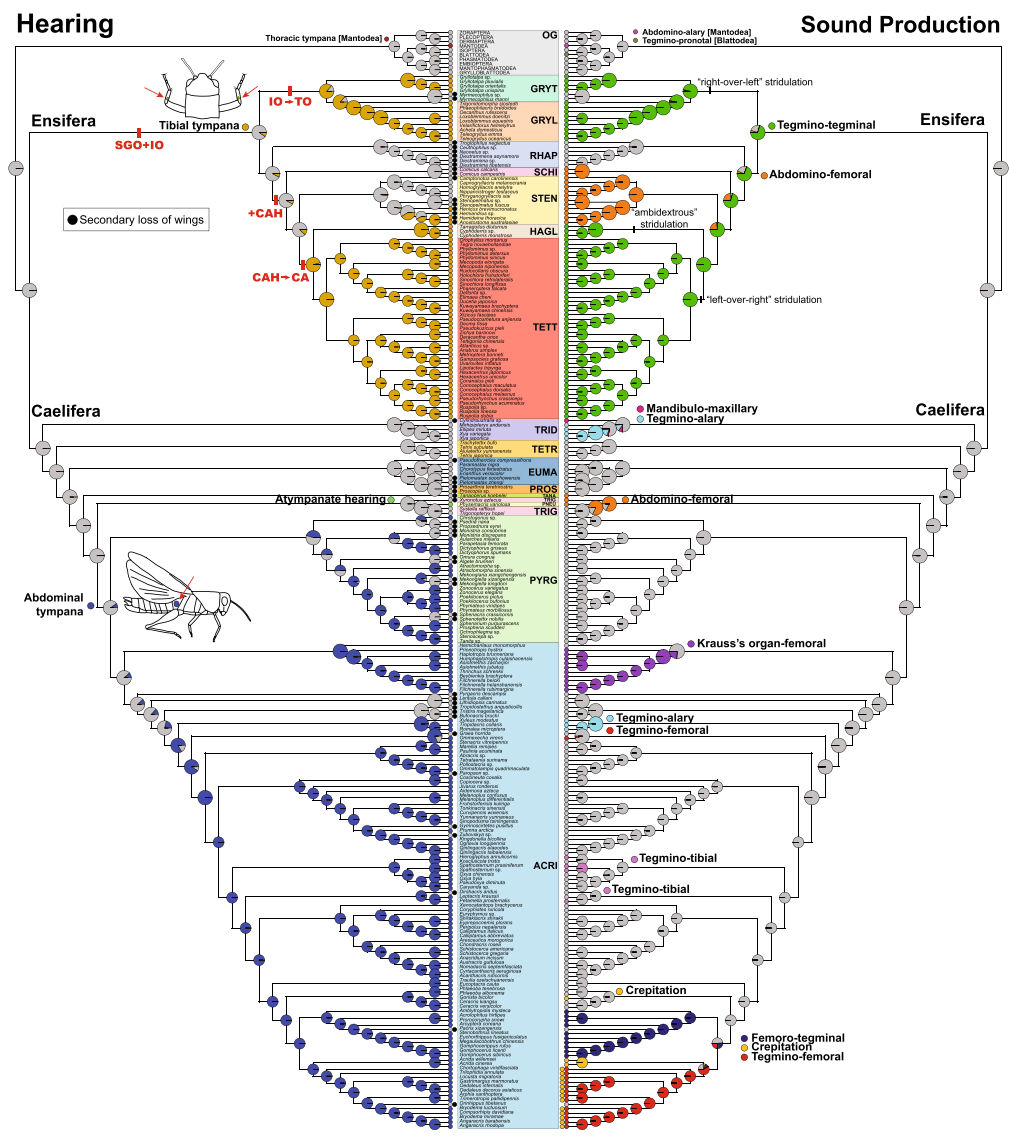


which replaces the previous incorrect version.

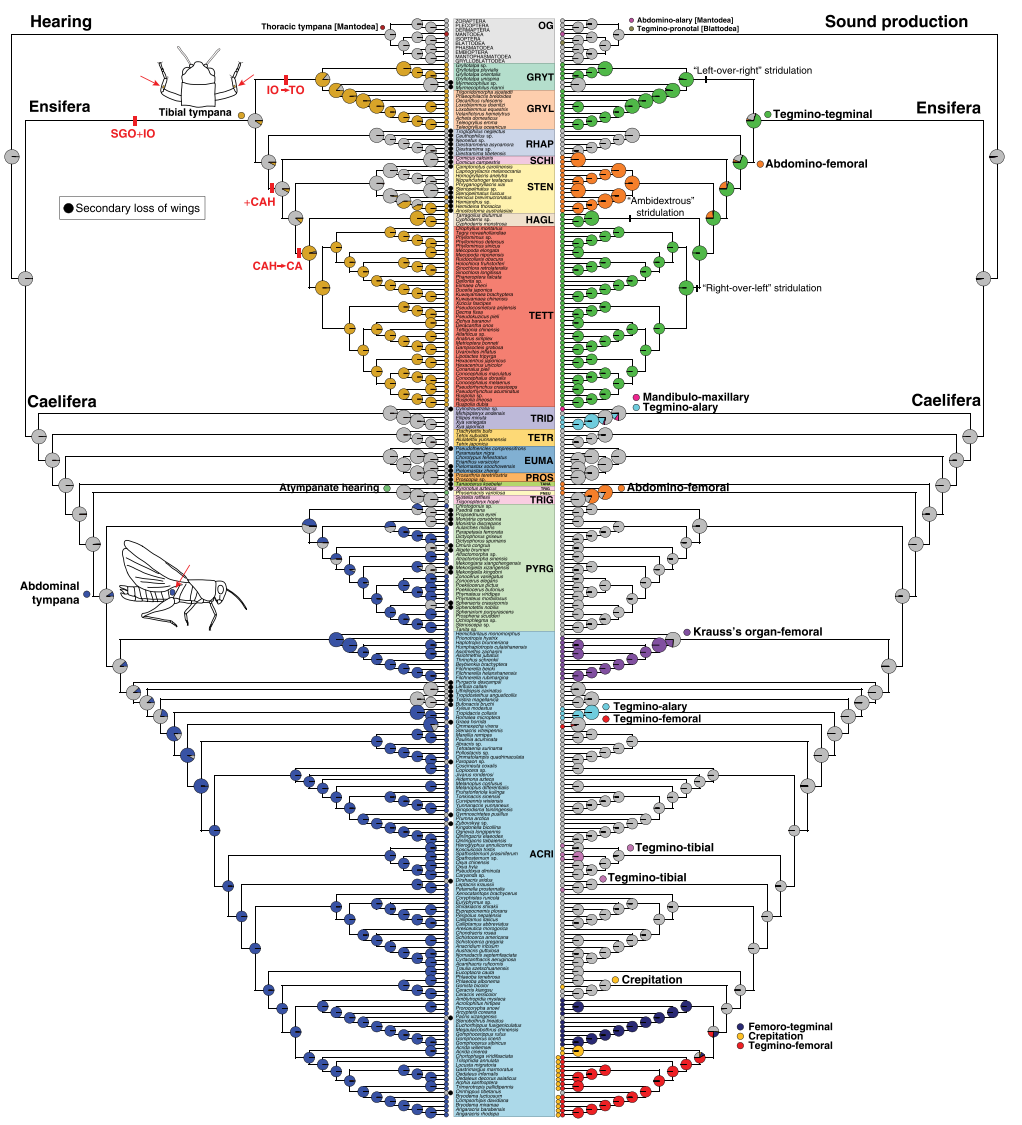

The original version of this Article contained an error in the last sentence of the Fig. 3 legend, which incorrectly read 'The common ancestor of Gryllidea evolved "left-over-right" stridulation, the common ancestor of Hagloidea evolved "ambidextrous" stridulation, and the common ancestor of Tettigonioidea evolved "right-over-left" stridulation'. The correct version replaces this sentence with 'The common ancestor of Gryllidea evolved "right-over-left" stridulation, the common ancestor of Hagloidea evolved "ambidextrous" stridulation, and the common ancestor of Tettigonioidea evolved "left-over-right" stridulation'.

The original version of this Article contained an error in the Discussion, which incorrectly read 'Crickets and mole crickets stridulate by moving the left forewing over the right, and katydids stridulate in the opposite way by moving the right forewing over the left ${ }^{43}$. The correct version replaces this sentence with 'Crickets and mole crickets stridulate by moving the right forewing over the left, and katydids stridulate in the opposite way by moving the left forewing over the right ${ }^{43}$.

This has been corrected in both the PDF and HTML versions of the Article.

Published online: 03 November 2020

Open Access This article is licensed under a Creative Commons Attribution 4.0 International License, which permits use, sharing, adaptation, distribution and reproduction in any medium or format, as long as you give appropriate credit to the original author(s) and the source, provide a link to the Creative Commons license, and indicate if changes were made. The images or other third party material in this article are included in the article's Creative Commons license, unless indicated otherwise in a credit line to the material. If material is not included in the article's Creative Commons license and your intended use is not permitted by statutory regulation or exceeds the permitted use, you will need to obtain permission directly from the copyright holder. To view a copy of this license, visit http://creativecommons.org/licenses/by/4.0/.
}

(C) The Author(s) 2020 